\title{
CCN activation experiments with adipic acid: effect of particle phase and adipic acid coatings on soluble and insoluble particles
}

\author{
S. S. Hings ${ }^{1}$, W. C. Wrobel ${ }^{1}$, E. S. Cross ${ }^{1}$, D. R. Worsnop ${ }^{2}$, P. Davidovits ${ }^{1}$, and T. B. Onasch ${ }^{1,2}$ \\ ${ }^{1}$ Department of Chemistry, Boston College, Chestnut Hill, MA 02467, USA \\ ${ }^{2}$ Aerodyne Research Inc., Billerica, MA 01821, USA
}

Received: 1 February 2008 - Published in Atmos. Chem. Phys. Discuss.: 4 March 2008

Revised: 19 May 2008 - Accepted: 23 May 2008 - Published: 15 July 2008

\begin{abstract}
Slightly soluble atmospherically relevant organic compounds may influence particle CCN activity and therefore cloud formation. Adipic acid is a frequently employed surrogate for such slightly soluble organic materials. The 11 published experimental studies on the CCN activity of adipic acid particles are not consistent with each other nor do they, in most cases, agree with the Köhler theory. The CCN activity of adipic acid aerosol particles was studied over a significantly wider range of conditions than in any previous single study. The work spans the conditions of the previous studies and also provides alternate methods for producing "wet" (deliquesced solution droplets) and dry adipic acid particles without the need to produce them by atomization of aqueous solutions. The experiments suggest that the scatter in the previously published $\mathrm{CCN}$ measurements is most likely due to the difficulty of producing uncontaminated adipic acid particles by atomization of solutions and possibly also due to uncertainties in the calibration of the instruments. The CCN activation of the small $\left(d_{m}<150 \mathrm{~nm}\right)$ initially dry particles is subject to a deliquescence barrier, while for the larger particles the activation follows the Köhler curve. Wet adipic acid particles follow the Köhler curve over the full range of particle diameters studied. In addition, the effect of adipic acid coatings on the CCN activity of both soluble and insoluble particles has also been studied. When a watersoluble core is coated by adipic acid, the CCN-hindering effect of particle phase is eliminated. An adipic acid coating on hydrophobic soot yields a $\mathrm{CCN}$ active particle. If the soot particle is relatively small $\left(d_{\text {core }} \leq 102 \mathrm{~nm}\right)$, the $\mathrm{CCN}$ activity of the coated particles approaches the deliquescence line of adipic acid, suggesting that the total size of the particle determines $\mathrm{CCN}$ activation and the soot core acts as a scaffold.
\end{abstract}

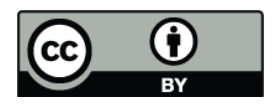

Correspondence to: S. S. Hings silkehings@gmail.com

\section{Introduction}

As has been discussed in several publications, the effect on climate of aerosol radiative forcing may be as large as that of the greenhouse gases, but opposite in sign and much more uncertain (See for example, Kaufman and Koren, 2006; Schwartz et al., 2007; IPCC, 2007). The high uncertainties are due to the currently inadequate representation of the complex interactions of aerosols with climate due to their intrinsically complex composition, morphology, and size distributions.

Atmospheric aerosol particles influence global climate by direct and indirect processes (Lohmann and Feichter, 2005). The direct process of aerosol climate-forcing involves the absorption, reflection, and scattering of incoming solar radiation by atmospheric aerosols. The indirect process involves atmospheric particles serving as cloud condensation nuclei $(\mathrm{CCN})$ on which water vapor condenses to form cloud droplets. CCN activity depends on the shape, size, structure, and composition of the aerosol particles (McFiggans et al., 2005; Dusek et al., 2006). An aspect of CCN activity is the subject of this work.

Slightly soluble organics, such as adipic acid, succinic acid, and stearic acid, are atmospherically relevant compounds that may significantly influence $\mathrm{CCN}$ activity and thus influence the indirect effect via cloud formation. Consequently, the $\mathrm{CCN}$ behavior of dicarboxylic acids has been studied extensively and has been found to vary widely (Cruz and Pandis, 1997; Corrigan and Novakov, 1999; Prenni et al., 2001; Giebl et al., 2002; Raymond and Pandis, 2002; Kumar et al., 2003; Bilde and Svenningsson, 2004; Broekhuizen et al., 2004; Huff Hartz et al., 2006; Rissman et al., 2007). For example, the $\mathrm{CCN}$ activity of oxalacetic acid is high, comparable to that of ammonium sulfate. On the other hand, suberic acid is CCN inactive. While the CCN behavior of some dicarboxylic acids such as succinic acid has been successfully predicted from Köhler theory modified to include solubility

Published by Copernicus Publications on behalf of the European Geosciences Union. 


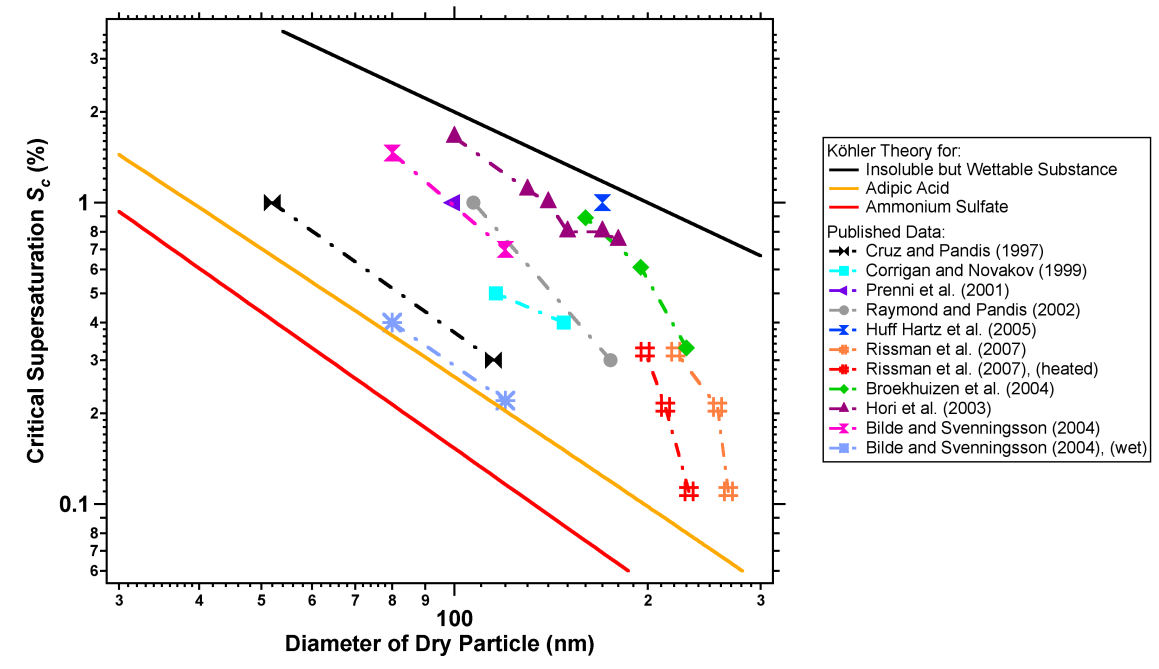

Fig. 1. Published critical supersaturations $\left(S_{c}\right)$ for adipic acid as a function of dry particle size. Particles were obtained by atomizing aqueous solutions. The source of the data is shown by the symbols as identified in the insert. The state of the particles prior to activation was dry unless otherwise noted. Critical supersaturations predicted by the standard Khler theory are shown as solid lines for $\left(\mathrm{NH}_{4}\right)_{2} \mathrm{SO}_{4}(\mathrm{red}$ line), adipic acid (orange line), and an insoluble but wettable substance (black line). See text for details.

and surface tension effects, published experimental studies on the CCN activity of slightly soluble adipic acid particles are in most cases not consistent with the Köhler theory and vary widely from one study to another. Adipic acid has a water solubility of $25 \mathrm{~g} / \mathrm{L}$ (Saxena and Hildemann, 1996).

It has been suggested and experimentally verified for several compounds (for example succinic acid and adipic acid) that particle phase plays an important role in the activation of particles consisting of slightly soluble organic compounds (Hori et al., 2003; Bilde and Svenningsson, 2004; Broekhuizen et al., 2004). Bilde and Svenningsson (2004) have also shown that small amounts of inorganic salts may have a significant effect on the percent critical supersaturation $\left(S_{c}\right)$ of slightly soluble organic compounds.

\subsection{Previously published $\mathrm{S}_{c}$ data for adipic acid}

Figure 1 shows published adipic acid critical supersaturation data as a function of particle diameter from 11 studies. In all these experiments, particles were formed by atomizing aqueous solutions of adipic acid. Particles were subsequently dried to relative humidities between 5 and $20 \%$. In one case only, particles were kept wet as supersaturated (i.e., deliquesced) solution droplets (designated in the figure as "wet"). In one set of experiments, Rissman et al. (2007) heated the adipic acid particles prior to drying them.

The solid lines are obtained from standard Köhler theory calculations described in Sect. 2. The orange line is the calculation for adipic acid using a concentration dependent surface tension. The red line is the calculation for ammonium sulfate particles and the solid black line is the Köhler curve for pure water that is a stand-in for a wettable but insoluble substance (Petters and Kreidenweis, 2007). The broken lines in the figure provide visual continuity for the experimental points.

As is evident from Fig. 1, the published data for adipic acid exhibit significant scatter. For example, at $1 \%$ supersaturation, measured critical diameters for adipic acid particles vary from $50 \mathrm{~nm}$ to $180 \mathrm{~nm}$. The measurements of Bilde and Svenningsson (2004) for wet particles fall close to the standard Köhler theory line for adipic acid. The measurements of Rissman et al. (2007) for the largest sized particles approach the predictions of the Köhler theory. All other data show higher critical supersaturations than predicted by the Köhler theory. The large variations in measured supersaturation are likely caused by particle phase differences (Bilde and Svenningsson, 2004), differences in particle preparation (Rissman et al., 2007), as will be discussed, and also possibly due to methods of $\mathrm{CCN}$ measurement (see Appendix).

The purpose of the present work, studying the CCN activity of adipic acid, is twofold. First, we want to understand the factors governing the $\mathrm{CCN}$ activity of slightly soluble organic compounds and, in the process, we want to explain the wide variations in the published critical supersaturation measurements for adipic acid. Toward these ends, we studied the $\mathrm{CCN}$ activity of adipic acid aerosol over a significantly wider range of conditions (particle diameter, particle phase, and particle coatings) than has been previously encompassed in any single study. Our work spans the conditions of the previous studies and also provides alternate methods for producing "wet" and dry adipic acid particles without the need to produce them by atomization of aqueous solutions.

After a very short residence time in the atmosphere most aerosol particles acquire a coating of one type or another. 
The second purpose of our work is to understand the effect of adipic acid coatings on both soluble and insoluble cores with respect to cloud droplet activation.

\section{Theory}

\subsection{Derivation of critical supersaturation}

Cloud droplets are formed when water aggregates on the surface of a pre-existing particle and causes unrestrained condensational growth. This condensational growth is controlled by the vapor pressure over a particle and is a function of both the curvature and the composition of the particle. Standard Köhler theory describes this condensational growth and provides an expression for equilibrium water vapor pressure over an aqueous solution droplet yielding an expression for the supersaturation ratio $S_{w}$ (Pruppacher and Klett, 1997):

$S_{w}=\frac{p}{p_{0}}=\gamma_{w} x_{w} \exp \left(\frac{4 M_{w} \sigma}{R T \rho_{w} d_{p}}\right)$

Here, $p$ is the vapor pressure of water over the solution droplet, $p_{0}$ is the equilibrium vapor pressure over a flat surface, $\gamma_{w}$ is the activity of water, $x_{w}$ is the mole fraction of water in the aqueous solution, $M_{w}$ is the molar mass of water, $\sigma$ is the surface tension of the solution droplet, $R$ is the universal gas constant, $T$ is the temperature, $\rho_{w}$ is the density of water, and $d_{p}$ is the diameter of the droplet at water vapor pressure $p$. This diameter will be designated as the solution droplet diameter.

The product $\gamma_{w} x_{w}$ represents the Raoult (or solution) effect, which increases with increasing wet diameter $d_{p}$. The exponential term represents the Kelvin (or curvature) effect, which decreases with increasing wet diameter. These two competing effects result in a maximum with respect to $d_{p}$ for Eq. (1) (See Fig. 2).

The term commonly used to describe particle growth by vapor condensation is supersaturation $(S$, in percent) defined as:

$S=\left(S_{w}-1\right) \cdot 100$

Figure 2 displays $S$ as a function of the solution droplet diameter $d_{p}$. The maximum of this curve is known as the critical supersaturation $\left(S_{c}\right)$. An aerosol particle is $\mathrm{CCN}$ active (i.e., grows into a cloud droplet) if the ambient supersaturation exceeds this maximum. Standard Köhler theory describes the activation of single-component aqueous solution droplets and is used here to model ammonium sulfate and completely dissolved adipic acid.

\subsection{Surface tension in calculating critical supersaturation}

As is evident from Eqs. (1) and (2), surface tension is a key parameter for calculating the supersaturation $\left(S_{w}\right)$ and therefore the critical supersaturation $\left(S_{c}\right)$. It has been shown that

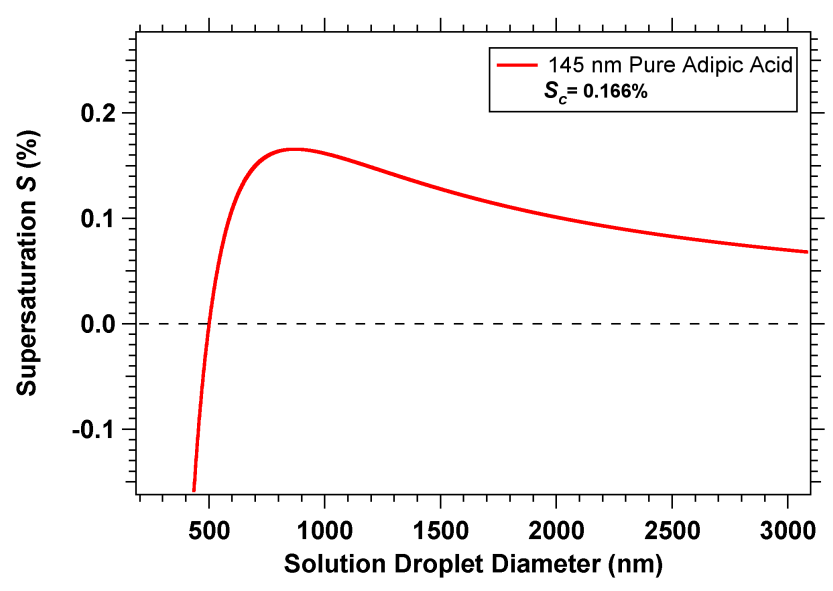

Fig. 2. Calculated supersaturation $S$ as a function of the solution droplet diameter $d_{p}$ for a particle composed of adipic acid. The adipic acid particle has dry diameter $145 \mathrm{~nm}$ and a critical supersaturation $S_{c}$ of $0.166 \%$.

dissolved surface active slightly soluble organic compounds can lower the surface tension of aqueous solutions, depending on concentration, by as much as one third (Shulman et al., 1996 and Facchini et al., 2000). A decrease in $\sigma$ lowers the critical supersaturation as predicted by Köhler theory.

The surface tension of an adipic acid solution can be calculated from the Szyszkowski-Langmuir equation as has been done by Henning et al. (2005):

$\sigma=\sigma_{w}(T)-a T \ln (1+b C)$

Here, $C$ is the concentration of dissolved carbon (moles of carbon per $\mathrm{kg}$ of water) and $\sigma_{w}(T)$ is the surface tension of water at temperature $T$. The parameters $a$ and $b$ are obtained by fitting the experimental results to Eq. (3). For pure adipic acid, Henning et al. (2005) obtained $a=0.0106$ and $b=11.836$.

\subsection{Results of critical supersaturation calculations}

Using Eqs. (1) and (2), critical supersaturations $S_{c}$ were calculated as a function of initially dry particle diameter for three substances: Ammonium sulfate, adipic acid, and an insoluble but wettable substance. Results are shown in Fig. 3. Ammonium sulfate is modeled using the surface tension of water $\left(0.072 \mathrm{~J} / \mathrm{m}^{2}\right)$. Adipic acid is modeled with both the concentration-dependent surface tension defined by the Szyszkowski-Langmuir equation (Eq. 3; ranging from $0.060-0.072 \mathrm{~J} / \mathrm{m}^{2}$ for $30-300 \mathrm{~nm}$ adipic acid particles) and the surface tension of water $\left(0.072 \mathrm{~J} / \mathrm{m}^{2}\right)$. The black line in Fig. 4 is the critical supersaturation for a pure water droplet. This line effectively models the growth of an insoluble but wettable spherical surface and is hereafter referred to as the "wettable line".

In the present work, the activation of ammonium sulfate particles coated by initially dry adipic acid is also studied. 


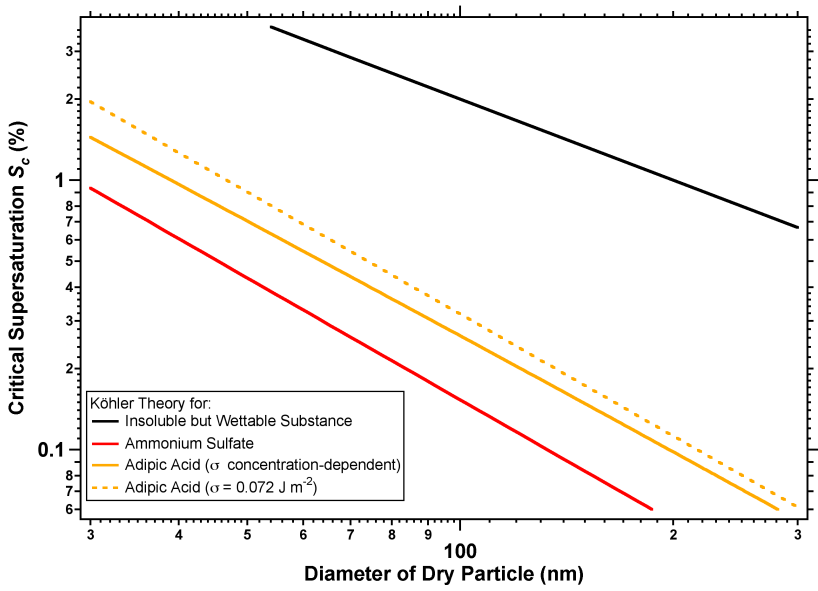

Fig. 3. Critical supersaturations as a function of initially dry particle diameter, calculated from Köhler theory for ammonium sulfate (red), adipic acid (yellow) and an insoluble but wettable substance (black). The lines for adipic acid have been modeled in two different ways: using the surface tension of water (dashed line) and using a concentration-dependent surface tension defined by the Szyszkowski-Langmuir equation (solid line). See text for details.

In such a case, the possibility exists that the droplet contains an undissolved adipic acid core surrounded by a solution of water, adipic acid, and ammonium sulfate. The presence of the ammonium sulfate allows condensational growth of the particle by addition of water without causing the complete deliquescence of the adipic acid. The presence of such a slightly soluble core that gradually dissolves as the droplet grows modifies the overall shape of the Köhler growth curve. Shulman et al. (1996) modified the standard Köhler theory to describe the effect of such a mixed composition on the activation of an aerosol particle into a cloud droplet. Our modeling calculations show that under our experimental conditions, the predictions of the standard and modified Köhler theories are the same.

2.4 Justification of solvent-free method for generating adipic acid

As has been stated, in all previous studies of adipic acid particle $\mathrm{CCN}$ activation, the adipic acid particles were generated by atomization of an aqueous solution (or methanol solvent Rissman et al., 2007). The process of atomization of a solution may introduce impurities that may be responsible for the variations in the $\mathrm{CCN}$ activity measured in the various studies. We decided to generate "wet" (deliquesced solution droplets) adipic acid without atomization. This section provides a theoretical justification for generating "wet" adipic acid particles by coating an ammonium sulfate core with adipic acid via vapor deposition. See Sect. 3.3 for the method of generating such particles.

In order to theoretically justify the solvent-free method for the generation of adipic acid particles, the $\mathrm{CCN}$ activity of ammonium sulfate particles was modeled as a function of sulfate core size and adipic acid coating thickness $(0-150 \mathrm{~nm})$. The calculated critical supersaturation of the dual-component aerosol ( $\left.S_{c, \text { dual }}\right)$ was compared to the predicted critical supersaturation for a single-component pure adipic acid particle $\left(S_{c, \text { pure }}\right)$ of the same diameter. The $S_{c, \text { dual }}$ values were calculated using modified Köhler theory with a concentration-dependent surface tension (Shulman et al. 1998 reported that the addition of $\left(\mathrm{NH}_{4}\right)_{2} \mathrm{SO}_{4}$ to adipic acid did not significantly alter the observed surface tension).

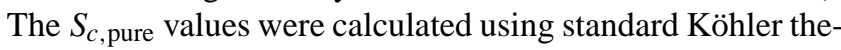
ory with a concentration-dependent surface tension. As the mass fraction of adipic acid increases, the relative error in using $S_{c, \text { dual }}$ to approximate $S_{c, \text { pure }}$ decreases (See Fig. 10, where the modeled ammonium sulfate-adipic acid lines are shown to approach the Köhler theory for pure adipic acid). The calculations show that above 0.85 mass fraction of adipic acid, the difference between the Köhler theory line for pure adipic acid and the Köhler sulfate-adipic is less than $10 \%$, for the range of ammonium sulfate core sizes studied in our experiments. This suggests that coating a small $\left(\mathrm{NH}_{4}\right)_{2} \mathrm{SO}_{4}$ core with a mass fraction of $>85 \%$ adipic acid via vapor deposition is a good approximation to experimentally obtain wet adipic acid points, as long as the mass fraction of the adipic acid is kept above 0.85 .

\subsection{Role of particle phase in activation of single- component aerosols}

Bilde and Svenningsson 2004) studied the role of phase in the CCN activation of adipic acid particles and found that deliquesced ("wet") adipic acid droplets activate at lower $S_{c}$ than initially dry adipic acid particles. Kreidenweis et al. (2006) suggested that below a certain particle diameter, deliquescence of initially dry organic compounds of low water-solubility occurs at higher water vapor pressure than the critical supersaturation for $\mathrm{CCN}$ activation. In such a case, there is an activation barrier to the onset of cloud droplet growth governed by the deliquescence of the organic species (Hori et al., 2003; Broekhuizen et al., 2004). Therefore, two $\mathrm{CCN}$ activation regimes are identified for particles composed of slightly soluble organic compounds. For larger particles, $\mathrm{CCN}$ activation is governed by the Köhler theory. For relatively smaller particles, the CCN activation is governed by the deliquescence transition. The deliquescence pressure ratio, given by (Pruppacher and Klett, 1997), is

$$
\frac{p}{p_{0}}=\gamma_{w} \exp \left(\frac{4 \sigma_{s a t} M_{w}}{d_{d} \rho_{w} R T}\right) .
$$

Here, $\sigma_{\text {sat }}$ is the surface tension of the saturated droplet, and $d_{d}$ the dry particle diameter. We note that the surface tension used in Eq. (4) is that of a saturated solution whereas in Eq. (1), the solution need not be saturated. 
The $\%$ deliquescence supersaturation $S_{\text {del }}$ is obtained in a way analogous to Eq. (2). For smaller particles and certain single-component, low water-soluble organic aerosols (including adipic acid) the parameter $S_{\text {del }}$ can be larger than the predicted critical supersaturation calculated via Eqs. (1) and (2). When $S_{\text {del }}>S_{c \text {,calculated, cloud-droplet activation is }}$ controlled by the deliquescence of the particles and activation occurs when the water vapor pressure is high enough to cause particle deliquescence, that is, $\mathrm{CCN}$ activation occurs at $S_{\mathrm{del}}$. However, when the condition is reached such that $S_{\mathrm{del}}<S_{c, \text { calculated, }}$, cloud-droplet activation occurs at $S_{c, \text { calculated. In short, a single-component adipic acid aerosol }}$ will only activate as a $\mathrm{CCN}$ after the particle has deliquesced. The water vapor pressure at which a particle deliquesces (at the calculated $S_{\text {del }}$ value) is also known as its deliquescence relative humidity (DRH). It must be noted that CCN activation can only occur at the $S_{d e l}$ when the particle is initially dry and when $S_{\text {del }}>S_{c \text {,calculated }}$. Initially wet particles have already deliquesced and therefore will activate at the $S_{c}$ value predicted by Köhler theory.

Figure 4 shows deliquescent supersaturations $S_{\mathrm{del}}$ as a function of dry particle diameter calculated from Eq. (4) using water activities of $\gamma_{w}=0.990$ and $\gamma_{w}=0.997$. As is evident from the figure, the deliquescent curves are strongly dependent on $\gamma_{w}$. For example, at $S_{\mathrm{del}}=0.3 \%$, a particle with a water activity of 0.990 will deliquesce at $165 \mathrm{~nm}$ whereas a particle with a water activity of 0.997 will deliquesce at diameter $298 \mathrm{~nm}$.

Reliable activity data for adipic acid are not available and therefore activity must be calculated based on solubility and molecular weight. Using a bulk solubility of $25 \mathrm{~g} / \mathrm{L}$, Kreidenweis et al. (2006) calculated the activity coefficient of adipic acid to be 0.997 . The quoted solubility is accurate to only two figures. Therefore, the activity coefficient is not likely to be more accurate. In Fig. 4 we show calculated deliquescence curves for activity coefficients of 0.990 (gray) and 0.997 (green). The indicated borders for each $\gamma_{w}$ are calculations with the two limits of surface tension quoted in the text ( $\sigma$ between 0.060 and $0.072 \mathrm{~J} / \mathrm{m}^{2}$ ). As is shown in Fig. 7, $\gamma_{w}=0.990$ provides a better fit to our experimental results.

\subsection{Determination of the particle shape factor}

Particle shape can greatly influence the $\mathrm{CCN}$ activity of atmospheric aerosols. Because the methods of aerosol generation used in this and other studies may produce particles that are not spherical, the shape factor needs to be considered in $\mathrm{CCN}$ activity measurements. Observation of the shape of nano-sized aerosol particles is usually performed with electron microscopy. Such observations are complicated because it is difficult to collect the particles without altering their shape. Several attempts were made to observe the particles used in this study with a scanning electron microscope. However, no consistent or reliable data were obtained. Therefore, tandem DMA-AMS measurements were used to measure the

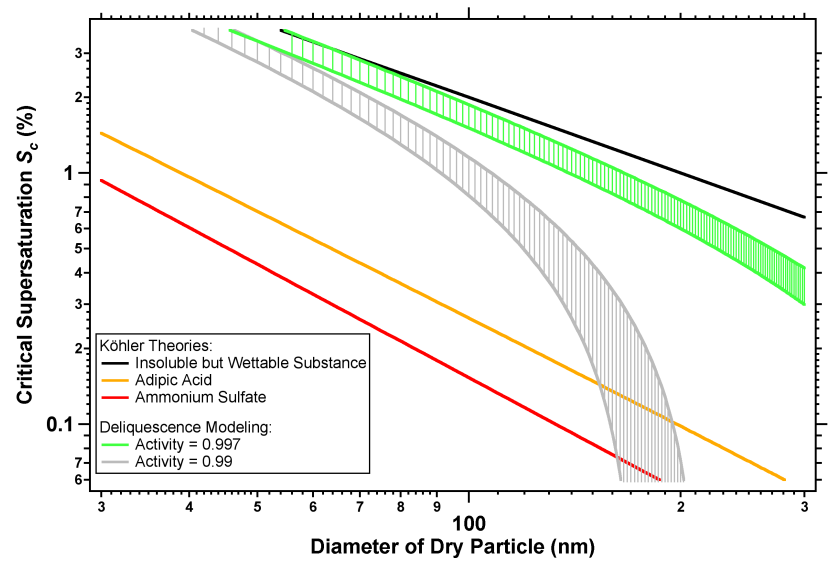

Fig. 4. Calculated deliquescent supersaturations $S_{\text {del }}$ (plotted on the $S_{c}$ axis) as a function of the dry particle diameter for adipic acid using water activities of 0.990 (gray) and 0.997 (green). The upper bound for each activity corresponds to a surface tension of $0.072 \mathrm{~J} / \mathrm{m}^{2}$ while the lower bound corresponds to a surface tension of $0.060 \mathrm{~J} / \mathrm{m}^{2}$.

dynamic shape factor. This method involves selecting particles by mobility and then sizing them aerodynamically in order to obtain information about particle shape. This procedure is described in detail in DeCarlo et al. (2004) and Slowik et al. (2004).

The general expression for relating $d_{v a}$ (vacuum aerodynamic diameter) and $d_{m}$ (mobility diameter) measurements is:

$$
\frac{\frac{d_{v a} \cdot \chi_{v} \cdot \chi_{t} \cdot \rho_{0}}{\rho_{p}}}{C_{c}\left(\frac{d_{v a} \cdot \chi_{v} \cdot \rho_{0}}{\rho_{p}}\right)}=\frac{d_{m}}{C_{c}\left(d_{m}\right)}
$$

Here, $\chi_{v}$ and $\chi_{t}$ are the dynamic shape factors in the free molecular and the transition regimes, $\rho_{0}$ is unit density, $\rho_{p}$ is the particle density, and $C_{c}(d)$ is the Cunningham slip correction factor. If one assumes that $\chi_{t}=\chi_{v}$ then for a known particle density $\rho_{p}$ (which is equal to $\rho_{m}$ for particles without internal voids), the dynamic shape factor $\chi$ of the particles can be estimated (DeCarlo et al., 2004). The dynamic shape factor $\chi$ is equal to unity for spherical particles without internal voids and larger than unity for nonspherical particles. Results of these shape factor determinations are discussed in Sect. 4.2.2.

\section{Experimental}

\subsection{Apparatus}

A schematic diagram of the experimental apparatus is shown in Fig. 5. The main components of the set-up are: A particle generation system, a particle coating system, two differential mobility analyzers (DMA I, TSI Model 3071A, and DMA II, TSI Model 3080), a condensation particle counter (CPC, 


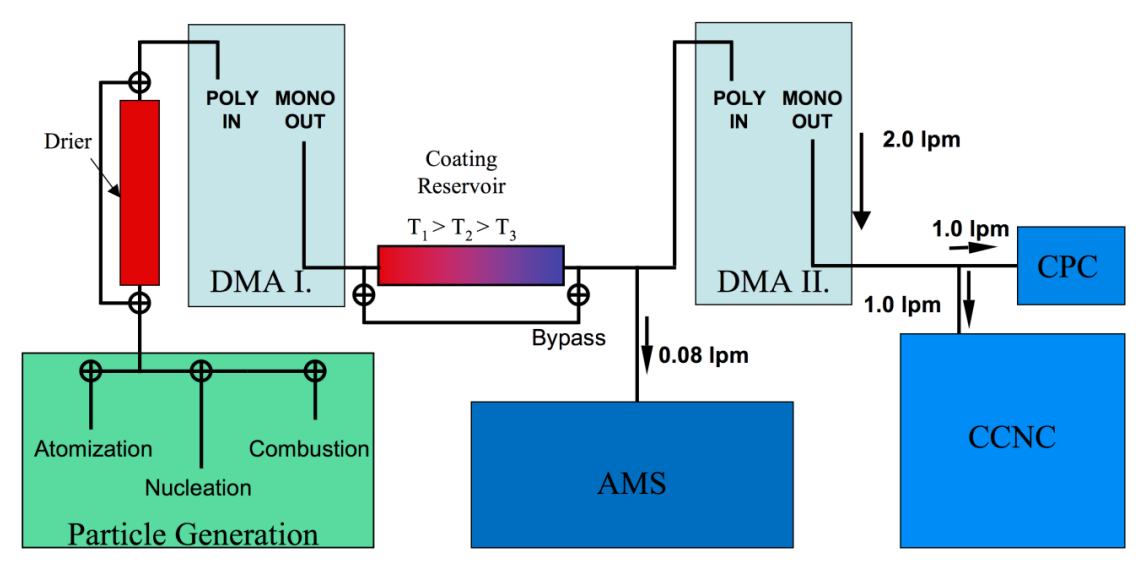

Fig. 5. Schematic of the experimental apparatus.

TSI Model 3010), a continuous-flow streamwise thermalgradient CCN counter (CCNC, Droplet Measurement Technologies), and a Time-of-Flight Aerosol Mass Spectrometer (ToF-AMS, Aerodyne Research Inc.).

With the exception of the CCNC apparatus, all instruments are either standard aerosol instrumentation or, in case of the ToF-AMS, are described in detail in the literature (Drewnick et al., 2005; DeCarlo et al., 2006).

\subsubsection{Cloud Condensation Nuclei Counter}

The DMT (Droplet Measurement Technologies) Cloud Condensation Nuclei Counter (CCNC) used in this study is operated in a continuous flow mode. That is, the instrument provides fast sampling by continually monitoring the $\mathrm{CCN}$ activity of the particles passing through it. The instrument is capable of generating nearly constant values of supersaturation between $0.07 \%$ and $3.7 \%$. The stated accuracy of these supersaturation values is $\pm 2 \%$. Supersaturation is easily controlled and maintained, making it possible to scan the full range of supersaturations for a given particle size.

The aerosol flow introduced into the CCNC instrument is split into an aerosol and a sheath flow. The sheath flow is filtered, humidified and heated. This sheath flow constrains the main aerosol flow to the centerline of the cylindrical CCNC column. The inner wall of the CCNC column is continually wetted and a positive temperature gradient $d T$ is applied to the CCNC column in the direction of the flow. Water vapor supersaturation is therefore generated along the centerline of the CCNC column (due to the difference in diffusion rates between water and heat). Particles begin to grow at the point when the supersaturation inside the instrument is equal to $S_{c}$. Droplets that grow to diameters larger than $1 \mu \mathrm{m}$ are detected by an optical particle counter (OPC) at the exit of the column and are defined as $\mathrm{CCN}$ active particles.

The supersaturation in the CCNC column is primarily a function of the temperature difference $(d T)$ between the top (upstream) and the bottom (downstream) of the CCNC col- umn. It also depends on the flow and the pressure inside the instrument. The relationship between supersaturation $(S)$ and the measured temperature difference $(d T)$ inside the $\mathrm{CCN}$ column is determined by calibration with ammonium sulfate particles at a specific flow and pressure. To obtain reliable experimental results, the CCNC apparatus has to be carefully calibrated in each specific application.

For a detailed description of the CCNC and its calibration, refer to Roberts and Nenes (2005), Lance et al. (2006), and Rose et al. (2007). Specific details relevant to our calibration measurements are presented in the Appendix.

\subsection{Experimental procedures}

As was stated, the previous 11 published studies of adipic acid generated the adipic acid particles by atomization of aqueous solutions. In order to explore the full range of experimental conditions, we generated particles both by atomization and by condensation of adipic acid vapor. The following measurements were performed to study the $\mathrm{CCN}$ activity of adipic acid. (1) CCN activity of dry adipic acid particles generated by atomization. (2) CCN activity of dry adipic acid generated by homogeneous nucleation (condensation of adipic acid vapor). (3) CCN activity of wet adipic acid particles generated by atomization. (4) CCN activity of wet adipic acid particles generated by vapor deposition of a mass fraction of $>85 \%$ adipic acid on small ammonium sulfate cores. (This method of generating wet adipic acid is discussed in detail.) (5) CCN activity of adipic acid coated on ammonium sulfate particles as a function of coating thickness. (6) CCN activity of adipic acid coated on soot particles as a function of coating thickness.

\subsection{Particle generation}

The methods of generating particles for the 6 studies listed in Sect. 3.2 are described below. If particles are to be dried, they are passed through diffusion driers as shown in Fig. 5. 
Table 1. Overview of particles studied with the method of particle generation. The dry and wet adipic acid are single-component adipic acid studies and the results are described in Sect. 4.2. The results of the adipic acid coating experiments are described in Sect. 4.3.

\begin{tabular}{llll}
\hline Particle Type & Dry Adipic Acid & Wet Adipic Acid & Adipic Acid Coating \\
\hline $\begin{array}{l}\text { Description of } \\
\text { Particle }\end{array}$ & (1) Atomization, & (3) Atomization, & (5) Vapor deposition of \\
Generation & followed by drying & no drying & $\begin{array}{l}\text { adipic acid on }\left(\mathrm{NH}_{4}\right)_{2} \mathrm{SO}_{4} \\
d_{m} \sim 50-250 \mathrm{~nm}\end{array}$ \\
& $d_{m} \sim 50-250 \mathrm{~nm}$ & $\begin{array}{l}d_{m} \sim 35-150 \mathrm{~nm} \\
\text { (three sulfate core sizes) }\end{array}$ \\
& (2) Homogenous & (4) Vapor acid & (6) Vapor deposition \\
& Nucleation & deposition of adipic & of adipic acid \\
& $d_{m} \sim 88-250 \mathrm{~nm}$ & on $\left(\mathrm{NH}_{4}\right)_{2} \mathrm{SO}_{4}$ & $d_{m} \sim 80-250 \mathrm{~nm}$ \\
& & $d_{m} \sim 70-150 \mathrm{~nm}$ & (four on soot particles) \\
\hline
\end{tabular}

The particles are size-selected by DMA I and, if they are to be coated, they are passed through the coating reservoir.

1. An aqueous solution of adipic acid in water is atomized to generate solution droplets. The aerosol flow is then heated $\left(\sim 60^{\circ} \mathrm{C}\right)$ and passed through three diffusion driers filled with silica gel.

2. Adipic acid particles are generated via homogeneous nucleation of adipic acid. Adipic acid is heated in a round bottom flask to approximately $150^{\circ} \mathrm{C}$. The airflow through the nucleation region is $2 \mathrm{~L} / \mathrm{min}$. The particles nucleate as the flow is passed through a cooled region. This method provides pure dry (solid) adipic acid particles.

3. An aqueous solution of adipic acid in water is atomized to generate solution droplets. The aerosol flow is not dried and the DMA sheath flow is humidified.

4. Adipic acid is dry-vapor deposited onto small dried ammonium sulfate particles. The ammonium sulfate core particles are generated by atomization of an aqueous solution. The particles are subsequently dried by passing them through a diffusion drier filled with anhydrous calcium sulfate (Drierite). The particles are then sizeselected by DMA I and passed through a region containing a heated adipic acid reservoir. In this region, the ammonium sulfate particles are coated by adipic acid via vapor deposition.

On entering the CCNC column, the highly water-soluble ammonium sulfate core absorbs enough water to completely dissolve the adipic acid, forming a concentrated adipic acidammonium sulfate aqueous solution. We postulate that water reaches the ammonium sulfate core either via diffusion through the adipic acid coating or by passage through imperfections in the coating. Experiments as well as calculations (See Sect. 2.4) show that if the mass fraction of the ammonium sulfate core is small $(<15 \%)$, this method provides an aerosol particle that, from the perspective of CCN activation, can be considered to be a single-component "wet" adipic acid particle.

5. For these experiments, adipic acid is coated onto ammonium sulfate cores as described above in Part (4).

6. item Soot particles are generated by combustion of ethylene and oxygen in a commercial McKenna burner (Slowik et al., 2004), and passed through a diffusion drier filled with activated carbon to remove flamegenerated organics. The particles are then size-selected and coated by vapor deposition of adipic acid.

For convenience, the 6 types of particles studied are presented in Table 1 along with the particle diameters studied for each particle type.

\subsection{Measurement of Particle CCN Activity}

After particle generation and size-selection, the aerosol flow is split with $2.0 \mathrm{~L} / \mathrm{min}$ directed into the DMA II and $0.08 \mathrm{~L} / \mathrm{min}$ into the ToF-AMS. Before and after each $\mathrm{CCN}$ experiment (i.e., every time a new particle size is selected), the second DMA and the CPC are used as a scanning mobility particle sizer (SMPS) to measure the size distribution of the particles. During a CCN experiment, the particles are size-selected a second time with DMA II in accord with the mode diameter determined during the SMPS scan. When the particles are pure adipic acid, the mode diameter is the same diameter as is selected with DMA I. However, when the particles are coated, the DMA II selects the coated mode diameter of the particles. The resulting monodisperse aerosol flow exiting DMA II is split between the CCNC $(1.0 \mathrm{~L} / \mathrm{min})$ and the CPC $(1.0 \mathrm{~L} / \mathrm{min})$ instruments.

The supersaturation in the CCNC is varied between $0.07 \%$ and $3.7 \%$ by setting the CCNC instrument $d T$ between 1.5 and $27 \mathrm{~K}$. During all experiments, the $\mathrm{CCNC}$ was operated at a total flow rate of $1 \mathrm{~L} / \mathrm{min}$. 


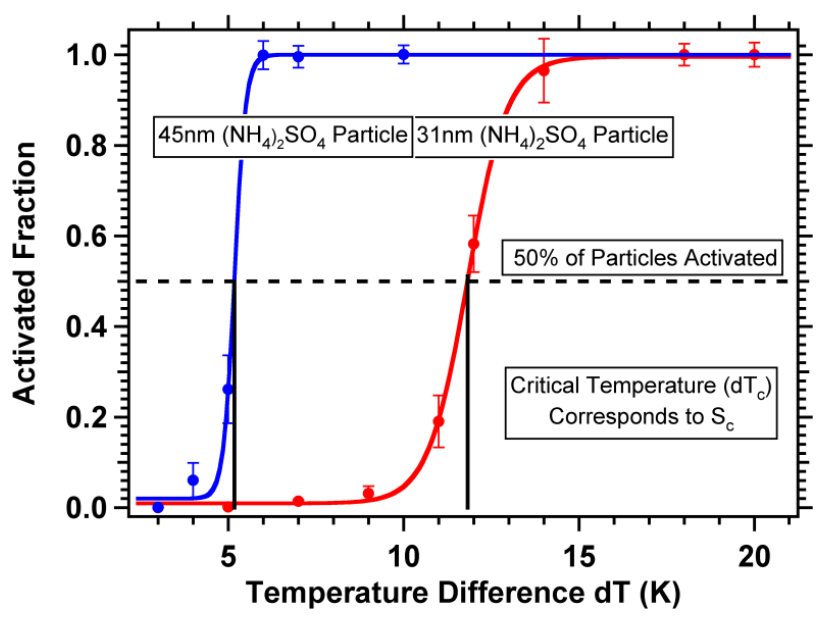

Fig. 6. Sample activation curves for $31 \mathrm{~nm}$ (red) and $45 \mathrm{~nm}$ (blue) ammonium sulfate particles. The critical supersaturation $\left(\mathrm{S}_{c}\right)$ calculated from the critical temperature $\left(\mathrm{dT}_{C}\right)$ is the supersaturation where $50 \%$ of the particles are activated.

The fraction of CCN activated aerosol is the ratio of the number concentration of $\mathrm{CCN}$ measured by the $\mathrm{CCNC}$ $\left(N_{\mathrm{CCN}}\right.$, i.e., number of particles that grow larger than $1 \mu \mathrm{m}$ as detected by the OPC) to the total number concentration of particles measured by the CPC $\left(N_{\mathrm{CPC}}\right)$. The critical supersaturation at a particular aerosol size is defined as the supersaturation at which $50 \%$ of the particles grow into droplets (i.e., when $=\frac{N_{\mathrm{CCN}}}{N_{\mathrm{CPC}}}=0.5$ ).

The method of determining the critical supersaturation $\left(S_{c}\right)$ is illustrated in Fig. 6 that shows examples of activation curves measured for ammonium sulfate particles of two diameters; $45 \mathrm{~nm}$ and $31 \mathrm{~nm}$. Such curves are generated by measuring the fraction of activated aerosol and plotting this number as a function of the temperature difference $d T$ in the CCNC column. The plot is fitted with a sigmoid function to find the critical temperature difference $\left(d T_{c}\right)$ where the activated fraction is 0.5 . The critical supersaturation is then calculated from the calibration curve described in the Appendix. The width of the sigmoidal curve is due to the spread in the aerosol size distribution determined by the DMA transmission function.

\section{Results and discussion}

\subsection{Overview}

The results of the CCN activation measurements are discussed in this section in the order presented in Sect. 3.3. The experimental results are discussed in the framework of the modeling calculations described in Sect. 2. The experimental studies described here fall into two categories: Single component adipic acid studies (corresponding to particle types (1), (2), (3) and (4) described in Sect. 3.3) and adipic acid coating studies (corresponding to particle types (5) and (6) in Sect. 3.3). Critical supersaturation $\left(S_{c}\right)$ values as a function of particle diameter were measured for each particle type $(1-6)$.

\subsection{Single-component adipic acid}

\subsubsection{Dry adipic acid particles generated by atomization}

In this set of experiments, we conducted $\mathrm{CCN}$ activation studies with adipic acid particles generated by atomization of adipic acid solutions over a range of particle diameters $\left(d_{m}\right)$ from $50 \mathrm{~nm}$ to $250 \mathrm{~nm}$ (described as particles type (1) and (3) in Sect. 3.3). About 15 such independent experimental $\mathrm{CCN}$ activation experiments were conducted. We were not able to obtain consistently reproducible data sets with adipic acid aerosols produced by atomization, nor were we able to ascertain the cause of this irreproducibility. Most likely the scatter in the data is due to trace impurities in the solution which we were not able to completely eliminate in spite of our best efforts.

\subsubsection{Homogenously nucleated dry adipic acid particles}

The results of $\mathrm{CCN}$ activation experiments with dry adipic acid particles generated by homogeneous nucleation of adipic acid vapor are shown in Fig. 7 as blue points, and correspond to particle type (2) described in Sect. 3.3. Here, the measured critical supersaturation $\left(S_{c}\right)$ is shown as a function of dry particle diameter $\left(d_{d}\right)$. Each critical supersaturation value in the figure is the average of at least three measurements for every dry particle diameter (the standard deviation is indicated by the error bars). Measurements were conducted over a period of several days to ensure reproducibility. The broken line provides visual continuity for the measured points. The standard deviation of the measurements is in all cases except one less than $4 \%$ of the measured $S_{c}$ values. As is evident, the homogenous nucleation method of generating adipic acid particles produces consistent results with little scatter.

The solid lines are the same calculated Köhler lines shown in Figs. 1 and 3. The shaded area models the deliquescence of the particles according to the Kelvin equation (Eq. 4) as discussed in Sect. 2.5. The surface tension of saturated aqueous adipic acid droplets larger than $40 \mathrm{~nm}$ is calculated to have values between 0.060 and $0.072 \mathrm{~J} / \mathrm{m}^{2}$ (See Eq. 3). A water activity over a saturated adipic acid solution of $\gamma_{w}=0.99$ was chosen to provide a best fit to the experimental data. The borders of the shaded region are obtained with the two limiting values of calculated surface tension $\left(0.060\right.$ and $\left.0.072 \mathrm{~J} / \mathrm{m}^{2}\right)$.

As is evident, the CCN activities of particles smaller than $150 \mathrm{~nm}$ in diameter are not governed by standard Köhler theory. The activation of the smaller particles more closely follows the predictions of the deliquescence calculations, although the fit is not exact. Still, the general trend in the 
Table 2. Estimated particle dynamic shape factors as a function of particle size for dry adipic acid generated by homogeneous nucleation.

\begin{tabular}{ll}
\hline$d_{m}$ & $\chi \pm \Delta_{\chi}$ \\
\hline 100 & $1.04 \pm 0.16$ \\
125 & $1.10 \pm 0.19$ \\
151 & $1.22 \pm 0.19$ \\
188 & $1.24 \pm 0.19$ \\
200 & $1.26 \pm 0.19$ \\
\hline
\end{tabular}

measurements for adipic acid particles smaller than $150 \mathrm{~nm}$ follows the deliquescence model, supporting the suggestion of Hori et al. (2003) and Kreidenweis et al. (2006) that deliquescence-controlled activation may govern droplet formation for small, slightly soluble organic particles. The smallest particle $\left(d_{m}=88 \mathrm{~nm}\right)$ in this set of measurements behaves as a particle composed of an insoluble wettable material. We could not obtain data for particles smaller than $d_{m} \sim$ $88 \mathrm{~nm}$ because to produce such small particles with our homogenous nucleation apparatus, we had to reduce the adipic acid vapor pressure to a point where the number of particles produced was too small to perform $\mathrm{CCN}$ experiments. The activation of particles larger than $\sim 150 \mathrm{~nm}$ follows standard Köhler theory.

As described in Sect. 2.6, the dynamic shape factor $\chi$ of the particles can be estimated from DMA/AMS size measurements via Eq. (5). The mobility diameter $\left(d_{m}\right)$ is measured by the DMA apparatus and the vacuum aerodynamic diameter $\left(d_{v a}\right)$ is measured by the AMS. Using the adipic acid bulk density of $1.36 \mathrm{~g} / \mathrm{cm}^{3}$, we estimate the dynamic shape factors to be as shown in Table 2. The use of bulk density in Eq. (5) assumes that the particle does not contain internal voids. This seems to be a reasonable assumption for particles that are formed by vapor condensation. The uncertainties in $\chi$ are primarily due to the uncertainty in the measured vacuum aerodynamic diameter $\left(d_{v a}\right)$, which is approximately $\pm 15 \%$. Within these error limits, the particles do not appear to deviate significantly from a spherical shape $(\chi=1.0)$.

\subsubsection{Comparison with previous studies}

In Fig. 8, we once again show the previously published CCN activation data for dry adipic acid aerosol. We also include our nucleation-generated dry adipic acid aerosol data in the figure.

As is evident, some of the published $S_{c}$ measurements are above and some are below our values. The wide scatter in the measured CCN activity obtained in the previous studies suggests that some significant parameter or parameters vary from experiment to experiment. Our experiments do not provide an explanation for these discrepancies, however we can

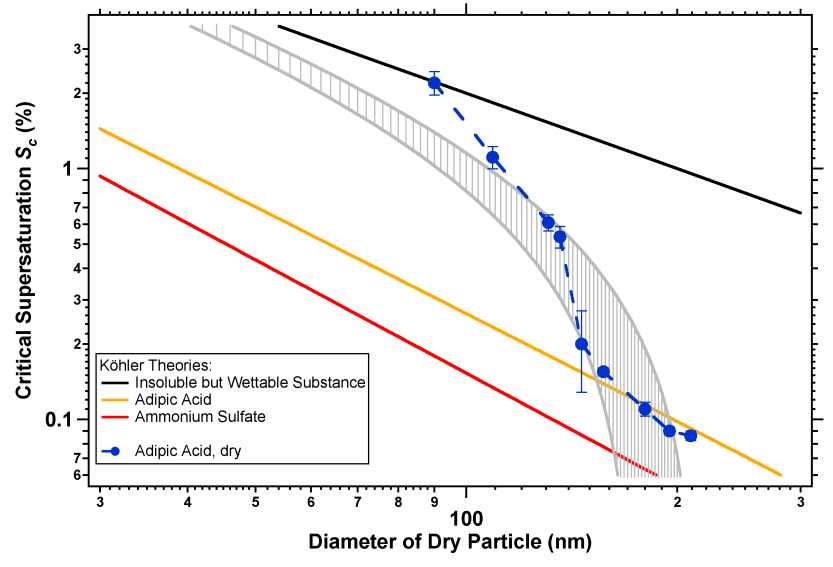

Fig. 7. $\mathrm{S}_{c}$ plotted as a function of particle diameter for dry adipic acid particles (blue symbols). Köhler theory lines are the same as in Figs. 1 and 3. The shaded area is the deliquescence region calculated from Eq. (4) with $\gamma_{w}=0.990$. The upper and lower bounds correspond to solution surface tensions of 0.072 and $0.060 \mathrm{~J} / \mathrm{m}^{2}$, respectively.

suggest some possible factors that may affect the results. Because all previously published experiments were performed with aerosol generated by atomization, we suggest that solution impurities are one possible cause of the scatter in the data. We note that all the previously obtained $S_{c}$ results fall above the Köhler curve. That is, they are all in the region where deliquescence governs the onset of activation. Therefore, if impurities are the cause of the scatter, they must be such that some promote and others hinder particle deliquescence.

Another possible reason for the scatter in the published measurements of $S_{c}$ may be related to the shape of the particles produced by the atomization and drying process. The volume-equivalent diameter $\left(d_{v e}\right)$ of a non-spherical particle is smaller than its electrical mobility diameter $\left(d_{m}\right)$ (DeCarlo et al., 2004). In all the published measurements, the reported diameter is the mobility diameter as measured by a DMA instrument. If the atomization-generated particles are nonspherical, their effective diameter is smaller than their measured $d_{m}$. Were this the case, the data points would be shifted to the left (i. e., to a smaller effective diameter) placing the published data closer to the results obtained in our studies. A possible confirmation of this hypothesis is provided by the data of Rissman et al. (2007). They show data for both heated and unheated adipic acid particles. The heated adipic acid particle data fall to the left of the unheated adipic acid data (i.e., the heated adipic acid particles have a smaller effective diameter than the unheated particles). This might be due to a reorganization of the adipic acid during heating, resulting in more spherical adipic acid particles.

As is shown in the Appendix, the calibration of the CCNC instrument is a critical part of these experiments. Slight miscalibrations of the CCNC instrument prevent accurate 


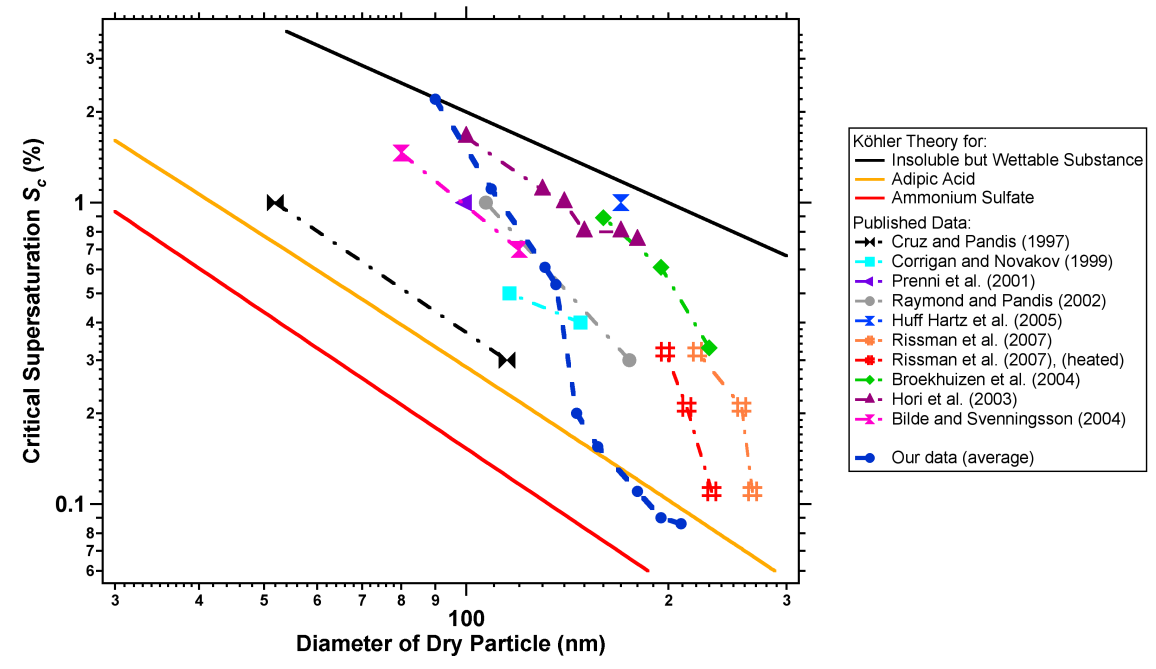

Fig. 8. $S_{c}$ plotted as a function of particle diameter for dry adipic acid particles from previously published studies (as in Fig. 1) shown together with our measurements.

measurements of $S_{c}$ values. Variations in the calibration of the $\mathrm{CCN}$ instrument from one experimental group to another cannot be ruled out as one of the causes for the scatter in the data.

\subsubsection{Wet adipic acid}

As is shown in Fig. 1, there is only one previously published CCN activation study for wet adipic acid aerosol particles. The results of the published study are in agreement with standard Köhler theory. As we stated earlier, we were not able to obtain consistent measurements with either wet or dry adipic acid aerosol produced by atomization. Most of our wet adipic acid measurements (from 5 independent runs) fell below the critical supersaturation predicted by the Köhler theory. We attribute the scatter in these data to residual impurities, most likely ammonia, which can play a role in experiments with wet adipic acid produced by atomization. The $\mathrm{CCN}$ activity of initially dry adipic acid, however, is reported to be unaffected by ammonia (Dinar et al., 2007).

To eliminate possible impurities in the adipic acid particles (such as, for example, contamination by ammonia resulting from the atomization process), we generated effectively wet adipic acid aerosol by coating small ammonium sulfate cores with adipic acid by vapor deposition (described as particle type (4) in Sect. 3.3). Experiments were conducted with three ammonium sulfate core sizes $\left(d_{\text {core }}=34 \mathrm{~nm}, 53 \mathrm{~nm}\right.$, $73 \mathrm{~nm}$ ) coated with adipic acid. In this subset of experiments, the adipic acid mass fraction was in all cases greater than 0.85 . Under these conditions, the calculated $S_{c}$ of the dualcomponent aerosol particle is the same to within $10 \%$ as the $S_{c}$ of a single-component adipic acid particle of equivalent diameter (see Sect. 2.4). A plot of $S_{c}$ as a function of wet adipic acid particle diameter is shown in Fig. 9. Data from

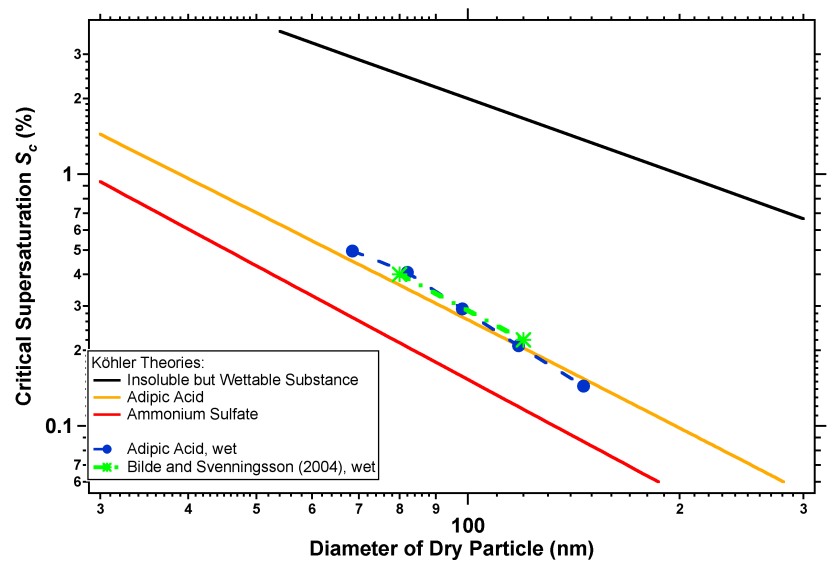

Fig. 9. Plot of $S_{c}$ as a function of wet adipic acid particle diameter. Data from present work are displayed as blue points. Data of Bilde and Svenningsson (2004) are shown as light blue stars.

the present work are displayed as blue points. Data of Bilde and Svenningsson (2004) are shown as light blue stars. As is evident, the data are in accord with standard Köhler theory.

\subsection{Adipic acid coating experiments}

\subsubsection{Ammonium sulfate coated with adipic acid}

In the coating studies, three ammonium sulfate particles of diameters $d_{\text {core }}=34,53$ and $73 \mathrm{~nm}$ were coated with adipic acid (coating thickness $\sim 5-34 \mathrm{~nm}$, described as particle type (5) in Sect. 3.3). The CCN activity of the coated particles was measured as a function of the total particle size (ammonium sulfate core + adipic acid coating). The results are shown in Fig. 10 as plots of $S_{c}$ as a function of total particle diameter. 


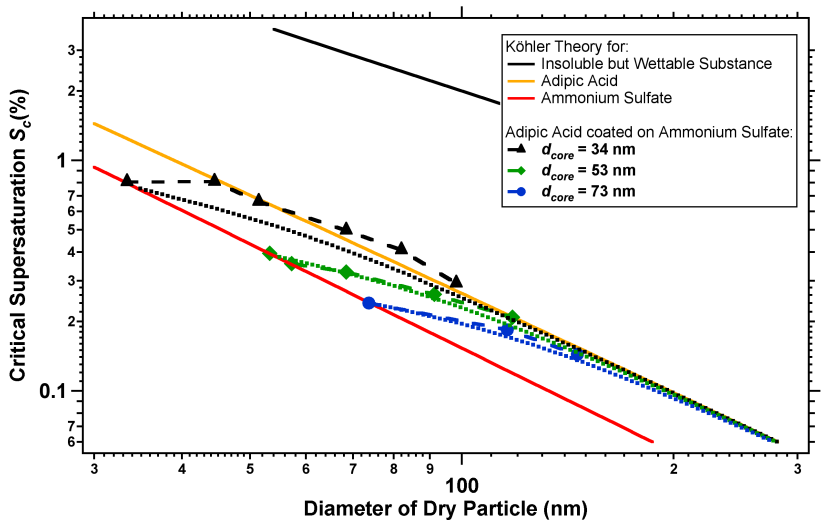

Fig. 10. $S_{c}$ plotted as a function of particle diameter for adipic acid coated ammonium sulfate particles of sizes $\mathrm{d}_{\text {core }}=34 \mathrm{~nm}$ (black), $53 \mathrm{~nm}$ (green) and $73 \mathrm{~nm}$ (blue) The dashed lines are calculated using Köhler theory.

The solid orange and red lines in the figure are the Köhler curves for pure adipic acid and pure ammonium sulfate, respectively. The dotted lines are results of calculations using modified Köhler theory, taking into account the combined activity of the solution.

In each case, the uncoated ammonium sulfate particle activates on the ammonium sulfate Köhler theory line, even though the particle is initially a dry solid. This is a case where the calculated $S_{c}$ is greater than the water vapor pressure at which particle deliquescence occurs (see Sect. 2.5). Ammonium sulfate particles deliquesce readily and the water vapor pressure in the CCNC instrument is always above the deliquescence vapor pressure for ammonium sulfate. As expected, with increasing adipic acid coating thickness, the measured $S_{c}$ values rise above the ammonium sulfate Köhler line and approach the adipic acid Köhler theory line. The endpoints in the adipic acid coating studies presented here are the $S_{c}$ data in Fig. 9 .

We note that the vapor deposited adipic acid coating is initially a dry solid. The results obtained here indicate that the addition of a hydrophilic soluble compound to dry adipic acid eliminates the effect of the deliquescence barrier to $\mathrm{CCN}$ activation that was observed for pure single-component dry adipic acid.

\subsubsection{Soot coated with adipic acid}

In this set of coating experiments, four soot particles of sizes $d_{\text {core }}=88 \mathrm{~nm}, 102 \mathrm{~nm}, 136 \mathrm{~nm}$ and $181 \mathrm{~nm}$ were coated with adipic acid (described as particle type (6) in Sect. 3.3). The uncoated soot particles generated by our hydrocarbon combustion source are $\mathrm{CCN}$ inactive in the supersaturation range of $0.07-3.7 \%$. The CCN activity of the soot coated with adipic acid was measured as a function of the adipic acid coating thickness $(<3-75 \mathrm{~nm})$. These experiments were per-

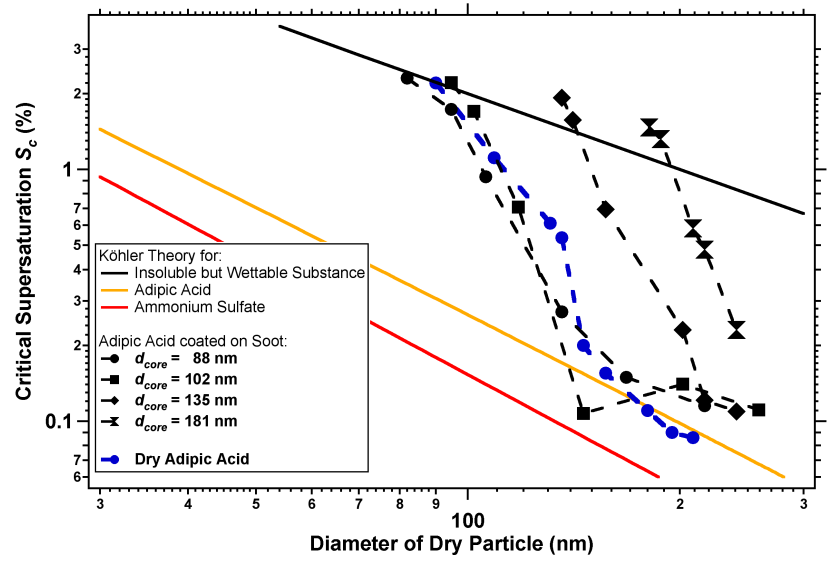

Fig. 11. $S_{c}$ plotted as a function of the total particle diameter (soot core + adipic acid coating) for adipic acid coated soot particles of sizes $\mathrm{d}_{\text {core }}=88 \mathrm{~nm}$ (diamonds), $102 \mathrm{~nm}$ (squares), $136 \mathrm{~nm}$ (triangles), and $181 \mathrm{~nm}$ (circles). Also included are the results for dry adipic acid obtained in this study (blue).

formed to measure the change in $\mathrm{CCN}$ activity when an insoluble hydrophobic core is coated with adipic acid.

Figure 11 shows the measured critical supersaturations as a function of the total particle diameter (soot core + adipic acid coating). Our CCN activation measurements for dry adipic acid particles are included for comparison.

The points at the tops of the activation lines are soot particles coated with very thin layers $(<3 \mathrm{~nm})$ of adipic acid. These data points indicate that a very small layer of adipic acid on a $\mathrm{CCN}$-inactive particle triggers $\mathrm{CCN}$ activation near (or above) the calculated critical supersaturations of a wettable solid core (the black line in Fig. 11).

As shown in the figure, the measured critical supersaturations for adipic acid coatings on smaller soot core sizes $\left(d_{\text {core }}=88 \mathrm{~nm}\right.$ and $\left.102 \mathrm{~nm}\right)$ approach the critical supersaturations measured for dry adipic acid. The particles activate at the deliquescence relative humidity DRH, or $S_{\mathrm{del}}$ of adipic acid. See Sect. 2.5. This suggests that the soot core acts as a scaffold for the adipic acid coating and deliquescence is determined by the total particle diameter. The soot-adipic acid particle acts as a pure adipic acid particle during $\mathrm{CCN}$ activation because the adipic acid completely coats the soot core. Here, the total size of the particle (and not the composition) governs $\mathrm{CCN}$ activation.

The $S_{c}$ measurements for the larger soot core sizes $\left(d_{\text {core }}=136\right.$ and $\left.181 \mathrm{~nm}\right)$ are displaced to the right of the dry adipic acid line. This indicates that the larger soot core sizes coated with adipic acid do not activate according to either the deliquescence or the standard Köhler theory for adipic acid. This observation seems to suggest that for these types of particles, the soot core does not simply act as a scaffold for the adipic acid coating. It appears that from the perspective of $\mathrm{CCN}$ activation, the effective diameter of the larger soot particles coated with adipic acid is less than the measured 
particle diameter. At this time we do not have a verifiable explanation for this observation. We suggest a possible reason for this difference between the $\mathrm{CCN}$ behavior of the larger and smaller coated soot particles as follows.

Since the soot itself is hydrophobic, water interacts only with the adipic acid coated onto the soot. Therefore, only the diameter of the adipic acid coating influences the $\mathrm{CCN}$ activity of the coated particle (producing an effective diameter). It is possible that the smaller soot cores are coated more thoroughly than the larger cores. A full coating yields an effective diameter equal to the total particle diameter. On the other hand, a partial coating may produce adipic acid "islands" with an effective diameter that is smaller than the total particle diameter. Other mechanisms related to shape and fractality factors could be suggested to explain the difference between small and large soot core sizes coated with adipic acid and thus, the $S_{c}$ measurements for the larger soot particles remain unexplained.

\section{Summary}

The CCN activity of both dry and "wet" (deliquesced solution droplets) adipic acid particles and the effect of adipic acid coatings on the CCN activity of soluble and insoluble particles were determined. The results of the experiments lead to the following conclusions:

1. In accord with earlier suggestions (Hori et al., 2003, and Kreidenweis et al., 2006), the CCN activation of small $\left(d_{m}<150 \mathrm{~nm}\right)$, dry slightly soluble organic particles is governed by the deliquescence of the particles (where $S_{\text {del }}>$ calculated $S_{c}$ ), and CCN activation follows the deliquescence curve for the particles. For larger dry particles, where $S_{\mathrm{del}}<$ calculated $S_{c}$, CCN activation follows the Köhler curve. As expected, "wet" adipic acid particles activate at the supersaturations predicted by Köhler theory for all sizes measured in this study (70-200 nm).

2. A solvent-independent method for generating pure organic particles (via homogeneous nucleation) was used for this study and found to provide results that were more reproducible than those obtained in our experiments as well as previously published experiments with particles produced by atomizing solutions. The homogeneously nucleated particles were measured to be nearly spherical $(\chi \leq 1.2)$. These results suggest that the observed scatter in the published literature for the $\mathrm{CCN}$ activity of adipic acid particles may be related to either the impurities in the solvents used or the inadvertent formation of non-spherical particles.

3. The experiments with adipic acid-coated ammonium sulfate aerosol particles indicate that the addition of a small mass fraction of a hydrophilic soluble compound (e.g. ammonium sulfate) to dry adipic acid particles eliminates the effect of particle phase on $\mathrm{CCN}$ activation, in agreement with Bilde and Svenningsson (2004).

4. An adipic acid coating on hydrophobic $\mathrm{CCN}$ inactive soot particle yields a $\mathrm{CCN}$ active particle at atmospherically relevant supersaturations. For relatively small soot cores $\left(d_{\text {core }}=88 \mathrm{~nm}\right.$ and $\left.102 \mathrm{~nm}\right)$, the CCN activity of the coated particles approaches the deliquescence line of adipic acid. This suggests that for coated soot particles in this range of diameters, the total size of the particle determines $\mathrm{CCN}$ activation and the soot core acts as a scaffold for the deposition of adipic acid vapor. It appears that the $\mathrm{CCN}$ activation of larger coated soot cores occurs at higher supersaturations than is predicted by the deliquescence curve. It is hypothesized that larger soot particles are only partially coated with adipic acid, causing the mixed particles to be chemical composition dependent, and not total particle size dependent as observed for small soot core sizes.

\section{Appendix A}

\section{CCN instrument calibration}

To perform reliable CCN activation measurements requires an accurate knowledge of the relationship between the temperature difference $d T$ along the CCNC column and the supersaturation $S$. This relationship is determined by calibration, using a well-characterized highly soluble inorganic salt, such as $\left(\mathrm{NH}_{4}\right)_{2} \mathrm{SO}_{4}$ or $\mathrm{NaCl}$. Previous studies have reported a linear relationship between instrument $d T$ and $S$ at a flow rate of $0.5 \mathrm{~L} / \mathrm{min}$ for $d T>3 \mathrm{~K}$. For smaller $d T$ the relationship becomes nonlinear (Rose et al., 2007; Droplet Measurement Technologies, 2004). In order to obtain a larger range of supersaturations, we calibrate and operate the instrument at flow rates between $0.5 \mathrm{~L} / \mathrm{min}$ and $1 \mathrm{~L} / \mathrm{min}$. All of the measurements done in this study were obtained with CCNC flow rates near $1 \mathrm{~L} / \mathrm{min}$.

The calibration arrangement is similar to that shown in Fig. 5. Calibration was done with ammonium sulfate aerosol particles generated by atomization of an aqueous solution of $\left(\mathrm{NH}_{4}\right)_{2} \mathrm{SO}_{4}$. The particles were dried to a relative humidity $(\mathrm{RH})<10 \%$ by passing the aerosol flow through diffusion driers. A narrow monodisperse size distribution $\left(d_{m} \pm 10 \%\right)$ was obtained by passing the particles through two Differential Mobility Analyzers (DMA I and DMA II). The aerosol flow was divided between the $\mathrm{CCNC}$ instrument and the condensation particle counter (CPC). Note that the CCNC counts the number of activated particles, while the CPC counts the total number of particles in the flow.

The following method was used to calibrate the CCNC instrument. Ammonium sulfate particles of a specific size $\left(d_{m}\right)$ flowed into the CCNC and CPC instruments. At a set value of $d T$, both the CCNC and the CPC particle counts were 


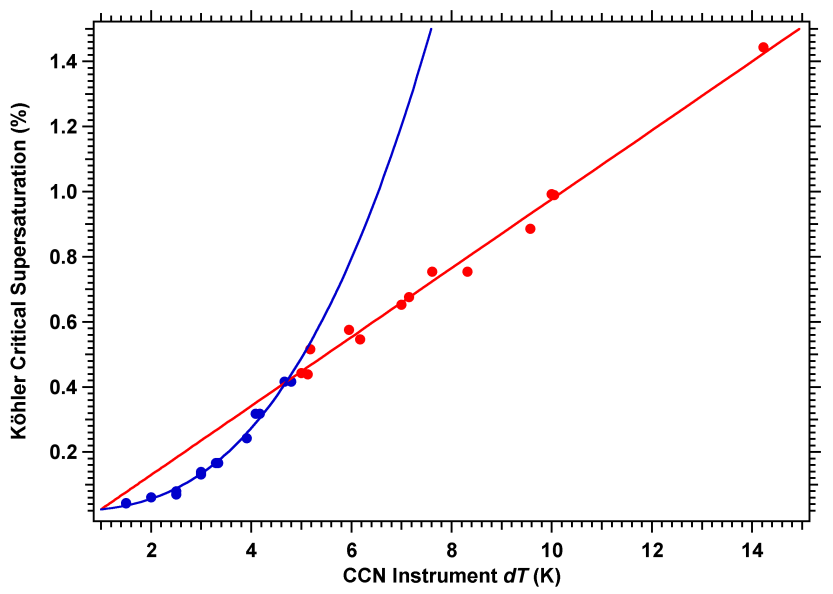

Fig. A1. Calculated critical supersaturation as a function of $\mathrm{CCN}$ instrument dTfor a flow rate of $0.93 \mathrm{~L} / \mathrm{min}$.

recorded. The value of $d T$ was systematically varied. Equilibration time between $d T$ settings was about $1 \mathrm{~min}$. The value of the critical $d T\left(d T_{c}\right)$ was recorded. ( $d T_{c}$ is the temperature difference at which $50 \%$ of the particles are activated.) Alternately, $d T$ was be kept constant while the particle diameter was systematically varied. Again, the $d T_{c}$ and the corresponding particle size were recorded. The two methods yielded similar results. The critical supersaturation $\left(S_{c}\right)$ was calculated for each particle size using standard Köhler theory (Eqs. 1 and 2). In this way, $S_{c}$ vs $d T_{c}$ calibration plots for the CCNC instrument were obtained.

The calibration curves for flow rates of $0.93 \mathrm{~L} / \mathrm{min}$ and $1 \mathrm{~L} / \mathrm{min}$ are shown in Figs. A1 and A2, respectively. These were the two flow rates used in our experiments. The nonlinear part of the curve was fitted to a power function:

$S_{c, 0}=y_{0}+A \cdot d T^{x}(A 1)$

Here, $S_{c, 0}, A$ and $x$ are parameters determined by the fit. As is evident, for $d T<5 \mathrm{~K}$, the calibration curves are nonlinear at both flow rates. As was stated, some earlier measurements found the onset of the nonlinear part of the calibration curve to be $d T<3 \mathrm{~K}$, implying that the calibration is instrument specific. While the transition to the nonlinear portion of the calibration curve appears to be insensitive to small changes in the flow rate, the slopes of the linear part of the curve are a sensitive function of the flow rate as is evident in the figures. For a flow rate of $0.93 \mathrm{~L} / \mathrm{min}$ the slope is $0.106 \% / \mathrm{K}$; for a flow rate of $1 \mathrm{~L} / \mathrm{min}$ it is $0.149 \% / \mathrm{K}$. This implies a $30-40 \%$ change in slope for a $\sim 7 \%$ change in flow rate. Thus, accurate measure and control of the flow rates used is very important. In the time period of the $\mathrm{CCN}$ experiments ( $\sim 8$ months) the calibration was periodically repeated and was found to remain constant for a given flow rate.

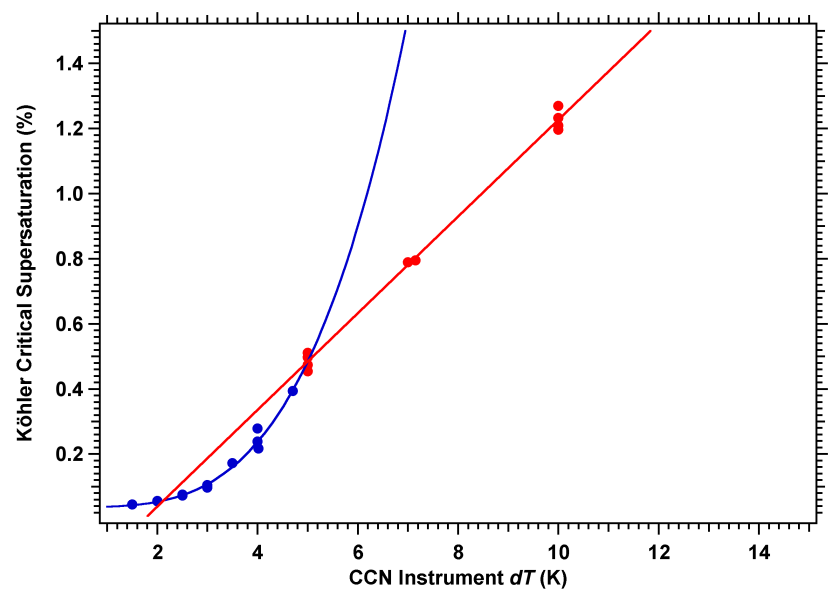

Fig. A2. Calculated critical supersaturation as a function of $\mathrm{CCN}$ instrument $\mathrm{dT}$ for a flow rate of $1 \mathrm{~L} / \mathrm{min}$.

Acknowledgements. This research was supported by the Office of Science (BER), Department of Energy (Atmospheric Science Program) grant No. DE-FG02-05ER63995 and the Atmospheric Chemistry Program of the National Science Foundation (NSF) grant No. ATM-0525355. The author ESC was funded by the NASA Earth System Science Fellowship program. We thank Sonia Kreidenweis for helpful discussions.

Edited by: J. Abbatt

\section{References}

Bilde, M. and Svenningsson, B.: CCN Activation of Slightly Soluble Organics: The Importance of Small Amounts of Inorganic Salt and Particle Phase, Tellus, 56 B, 128-134, 2004.

Broekhuizen, K., Kumar, P. P., and Abbatt, J. P. D.: Partially soluble organics as cloud condensation nuclei: Role of trace soluble and surface active species, Geophys. Res. Lett., 31, L01107, doi:01110.01029/02003GL018203, 2004.

Cruz, C. N. and Pandis, S. N.: A Study of the Ability of Pure Secondary Organic Aerosol to act as Cloud Condensation Nuclei, Atmos. Environ., 31, 2205-2214, 1997.

Corrigan, C. E. and Novakov, T.: Cloud Condensation Nucleus Activity of Organic Compounds: A Laboratory Study, Atmos. Environ., 33, 2661-2668, 1999.

DeCarlo, P. D., Slowik, J. G., Worsnop, D. R., Davidovits, P., and Jimenez, J. L.: Particle Morphology and Density Characterization by Combined Mobility and Aerodynamic Diameter Measurements. Part 1: Theory, Aerosol Sci. Technol., 38, 11851205, doi:10.1080/027868290903907, 2004.

DeCarlo, P. F., Kimmel, J. R., Trimborn, A., Northway, M. J., Jayne, J. T., Aiken, A. C., Gonin, M., Fuhrer, K., Horvath, T., Docherty, K., Worsnop, D. R., and Jimenez, J. L.: Field-Deployable, HighResolution, Time-of-Flight Aerosol Mass Spectrometer, Anal. Chem., 78 8281-8289, 2006.

Dinar, E., Anttila, T., and Rudich, Y.: CCN Activity and Hygroscopic Growth of Organic Aerosols Following Reactive Uptake 
of Ammonia, Environ. Sci. Technol., 42, 3, 793-799, 2008.

Drewnick, F., Hings, S. S., DeCarlo, P. F., Jayne, J. T., Gonin, M., Fuhrer, K., Weimer, S., Jimenez, J. L., Demerjian, K. L., Borrmann, S., and Worsnop, D. R.: A New Time-of-Flight Aerosol Mass Spectrometer (ToF-AMS) - Instrument Description and First Field Deployment, Aerosol Sci. Technol., 39, 637-658, 2005.

DMT: Cloud Condensation Nuclei Counter Operator Manual DOC0086 Revision A12, Droplet Measurement Technologies Inc., 2004.

Dusek, U., Frank, G. P., Hildebrandt, L., Curtius, J., Schneider, J., Walter, S., Chand, D., Drewnick, F., Hings, S., Jung, D., Borrmann, S., and Andreae, M. O.: Size matters more than chemistry for cloud nucleating ability of aerosol particles, Science, 312, 1375-1378, 2006.

Facchini, M. C., Decesari, S., Mircea, M., Fuzzi, S., and Loglio, G.: Surface Tension of Atmospheric Wet Aerosol and Cloud/Fog Droplets in Relation to their Organic Carbon Content and Chemical Composition, Atmos. Environ., 34, 4853-4857, 2000.

Giebl, H., Berner, A., Reischl, G., Puxbaum, H., Kasper-Giebl, A., and Hitzenberger, R.: CCN Activation of Oxalic and Malonic Acid Test Aerosols with the University of Vienna Cloud Condensation Nuclei Counter, Aerosol Sci., 33, 1623-1634, 2002.

Henning, S., Rosenoern, T., D’Anna, B., Gola, A. A., Svenningsson, B., and Bilde, M.: Cloud Droplet Activation and Surface Tension of Mixtures of Slighlty Soluble Organics and Inorganic Salt, Atmos. Chem. Phys., 5, 575-582, 2005, http://www.atmos-chem-phys.net/5/575/2005/.

Hori, M., Ohta, S., Murao, N., and Yamagata, S.: Activation Capability of Water Soluble Organic Substances as CCN, Aerosol Sci., 34, 419-448, 2003.

Huff Hartz, K. E., Tischuk, J. E., Chang, M. N., Chang, C. K., Donahue, M. N., and Pandis, S. N.: Cloud Condensation Nuclei Activation of Limited Solubility Organic Aerosol, Atmos. Environ., 40, 605-617, 2006.

IPCC: Climate Change 2007: The Physical Science Basis, in: Contribution of Working Group I to the Fourth Assessment Report of the Intergovernmental Panel on Climate Change, edited by: Solomon, S., Qin, D., Manning, M., Chen, Z., Marquis, M., Averyt, K. B., Tignor, M., and Miller, H. L., Cambridge University Press, Cambridge, UK and New York, NY, USA, 996 pp., 2007.

Kaufman, Y. J. and Koren, I.: Smoke and Pollution Aerosol Effect on Cloud Cover, Science, 313, 655-658, 2006.

Kreidenweis, S. M., Petters, M. D., and DeMott, P. J.: Deliquescence-Controlled Activation of Organic Aerosols, Geophys. Res. Lett. , 33, L068801, doi:10.1029/2005GL024863, 2006.

Kumar, P. P., Broekhuizen, K., and Abbatt, J. P. D.: Organic Acids as Cloud Condensation Nuclei: Laboratory Studies of Highly Soluble and Insoluble Species, Atmos. Chem. Phys., 3, 509-520, 2003, http://www.atmos-chem-phys.net/3/509/2003/.

Laaksonen, A., Korhonen, P., Kulmala, M., and Charlson, R. J.: Modification of the Köhler Equation to Include Soluble Trace Gases and Slightly Soluble Substances, J. Atmos. Sci., 55, 853$862,1998$.

Lance, S., Medina, J., Smith, J. N., and Nenes, A.: Mapping the Operation of the DMT Continuous Flow CCN Counter, Aerosol Sci. Technol., 40, 242-254, 2006.
Lohmann, U. and Feichter, J.: Global Indirect Aerosol Effect: a Review, Aerosol Chem. Phys. 5, 715-737, 2005.

McFiggans, G., Artaxo, P., Baltensperger, U., Coe, H., Facchini, M. C., Feingold, G., Fuzzi, S., Gysel, M., Laaksonen, A., Lohmann, U., Mentel, T. F., Murphy, D. M., O’Dowd, C. D., Snider, J. R., and Weingartner, E.: The effect of physical and chemical aerosol properties on warm cloud droplet activation, Atmos. Chem. Phys., 6, 2593-2649, 2006, http://www.atmos-chem-phys.net/6/2593/2006/.

Petters, M. D. and Kreidenweis, S. M.: A Single Parameter Representation of Hygroscopic Growth and Cloud Condensation Nucleus Activity, Atmos. Chem. Phys., 7, 1961-1971, 2007, http://www.atmos-chem-phys.net/7/1961/2007/.

Prenni, A. J., DeMott, P. J., Kreidenweis, S. M., Sherman, D. E., Russell, L. M., and Ming, Y.: The Effects of Low Molecular Weight Dicarboxylic Acids on Cloud Formation, J. Phys. Chem A, 105, 11 240-11248, 2001.

Pruppacher, H. R. and Klett, J. D.: Microphysics of Clouds and Precipitation, second ed., 714 pp., D. Reidel Publishing Company, Dordrecht, Holland, 1997.

Raymond, T. M. and Pandis, S. N.: Formation of Cloud Droplets by Multicomponent Organic Particles, J. Geophys. Res., 4469, 108, doi:10.1029/2003JD003503, 2002.

Rissman, T. A., Varutbangkul, V., Surratt, J. D., Topping, D. O., McFiggans, G., Flagan, R. C., and Seinfeld, J. H.: Cloud Condensation Nucleus (CCN) Behavior of Organic Aerosol Particles Generated by Atomization of Water and Methanol Solutions, Atmos. Chem. Phys., 7, 2949-2971, 2007, http://www.atmos-chem-phys.net/7/2949/2007/.

Roberts, G. C. and Nenes, A.: A Continuous-Flow Streamwise Thermal-Gradient CCN Chamber for Atmospheric Measurements, Aerosol Sci. Technol., 39, 206-221, 2005.

Rose, D., Frank, G. P., Dusek, U., Gunthe, S. S., Andreae, M. O., and Pöschl, U.: Calibration and Measurement Uncertainties of a Continuous-Flow Cloud Condensation Nuclei Counter (DMTCCNC): CCN Activation of Ammonium Sulfate and Sodium Chloride Aerosol Particles in Theory and Experiment, Atmos. Chem. Phys. Discuss., 7, 8193-8260, 2007, http://www.atmos-chem-phys-discuss.net/7/8193/2007/.

Saxena, P. and Hildemann, L. M.: Water-soluble organics in atmospheric particles: A critical review of the literature and application of thermodynamics to identify candidate compounds, J. Atmos. Chem., 24, 57-109, doi:110.1007/BF00053823, 1996.

Schwartz, S. E., Charlson, R. J., and Rhode, H.: Quantifying Climate Change - Too Rosy a Picture?, Nature Reports Climate Change, 2, 23-24, 2007.

Shulman, M. L., Jacobson, M. C., Carlson, R. J., Synovec, R. E., and Young, T. E.: Dissolution Behavior and Surface Tension Effects of Organic Compounds in Nucleating Cloud Droplets, Geophys. Res. Lett., 23, 277-280, 1996.

Slowik, J. G., Stainken, K., Davidovits, P., Williams, L. R., Jayne, J. T., Kolb, C. E., Worsnop, D. R., Rudich, Y., DeCarlo, P. F., and Jimenez, J. L.: Particle Morphology and Density Characterization by Combined Mobility and Aerodynamic Diameter Measurements. Part 2: Application to Combustion-Generated Soot Aerosols as a Function of Fuel Equivalence Ratio, Aerosol Sci. Technol., 38, 1206-1222, 2004. 